\title{
Diversification versus concentration analysis in specific economic activities for assessing spatial differentiation within local markets
}

\author{
Gheorghe Săvoiu ${ }^{1}$, and Alexander Vilgelm²* \\ ${ }^{1}$ University of Pitesti, Faculty of Economic Sciences and Law, Accounting, Finance and Economics \\ Department, 1st, Targul din Vale, Street, Pitesti, 110040, Romania \\ ${ }^{2}$ Khakas State University N.F. Katanova, 90 Lenin str., Abakan, 655017, Russian Federation
}

\begin{abstract}
Diversification and concentration represent essential two opposite trends in many economic phenomena. Monopoly and monopsony are the natural limits in any market's analysis and describe together the range or the amplitude of offer and demand in economics. A lot of statistical indicators or coefficients, quantifying the diversification versus concentration phenomenon (D vs. C), can reveal a market, optimal or not, full or empty, etc. The paper sheds the light on the relatively little explored concept of economic evolution from concentration to diversification across local markets, providing novel evidence on underlining the dominance of diversification process within regions. This paper has applied statistical structure variable-based methods for assessing spatial differentiation degree within housing construction economic activity in macroregion Siberia for the sample period from 2000:Q1 to 2020:Q4. We present empirical elasticities using the multivariate OLS model that summarize the diversification economic response to the increasing processes of urbanization and localization across the Siberian regions. Some final remarks offer a distinct profile of this Russian macroregion under the influence of demographical variability.
\end{abstract}

Keywords: diversification, concentration, spatial differentiation, local markets, regional economics.

\section{Introduction}

In this paper the authors shed the light on the relatively little explored concept of economic evolution from concentration to diversification across local markets, providing the novel evidence on underlining the dominance of diversification pro-cess within developing markets or the diversification versus concentration process (D vs. C phenomenon).

Systemic statistical analysis focused on identifying diverse populations under the impact of a phenomenon of diversification versus concentration (D vs. C) seems to be closer to the pleonasm or the fast thinking of Kahneman [1] specific way of criticism economics, frequently generating biases or systematic statistical errors. Although statistical

* Corresponding author: asvilhelm@gmail.com 
analyzes consistently use many indicators in quantifying the D vs. C phenomenon, many questions arise regarding the specificity of this systemic approach to frequency distributions or data series. Are indeed only one- or only bi-dimensional series of data useful for understanding $\mathrm{D}$ vs. C phenomenon? Is it or is it not a real possibility to select the best graphical statistical tools or tables, curves or areas, indices or coefficients, culminating with the adequate form to the new series of qualitative data, and thus generating statistics in the form of a series of attributes? Are or are not affected the statistical results of the D vs. C phenomenon's analysis by characteristic errors, generated by the substitution of the real values with the medians of variation intervals or with many other substitution indicators? Is the bias in a small proportion and with an insignificant impact in relation to the major advantages of the final structural knowledge of the investigated populations? After this brief introduction, including some major questions of the paper's research, emphasizing the importance of D vs. C analysis tools, this paper practically describes in post-introductory sections the general methodology of statistical calculation, as well as the applicability to the housing construction market in the Siberian macro-region. The paper remains an attempt to obtain revealing results and discuss the real contribution of the structural and systemic knowledge of a well-individualized socio-economic phenomenon like the housing construction market in Siberia as a distinct market.

Diversification is also an indicator of transformation processes of economic activity in the spatial aspect. For such indicators as, for example, the productivity of the construction industry, is an indicator at the local level not only of economic activity, but also an indicator of solvent demand, the development of local industries for the production of building materials, the use of the resource potential of the region, the development of localization and urbanization processes, spillovers, etc. [2, 3] Proceeding from definition of diversification in terms of spatial economics and New economic geography [4], we make an assumption that the emergence of new and development of existing types of economic activity is inextricably linked with such spatial aspects as the development of local markets under the influence of the activity of competitive economic agents within individual regional industries and local emerging markets [5-8]. Determination of the most significant factors of concentration and diversification of occurring processes on the territory of macro-regions allows to determine methodological tools in regional development programs. Scenario calculations as part of the development at the local and regional level will allow the government to improve the existing methodology for selecting the forms and methods of providing government support. However we will limit ourselves to identifying factors and trends in macro-regions that have similar natural and climatic conditions to Siberia and socio-economic factors that constitute its potential [9]. Thus, our assessment methodology helps to determine the main directions of development and implementation of the local potential of industries and areas to ensure regional economic growth through the balance of diversification and concentration processes [10,11].

The remaining sections of the paper are organized as follows. Section 2 presents an overview of related previous studies on the determinants of diversification in Siberia. Section 3 explains the econometric methodology and Section 4 the data used for examining the relationship between factors of diversification of regional economies and concentration of local construction market. Section 5 analyses the relationship for the middle-run by using OLS modeling and presents empirical results. Section 6 summarizes our findings and concludes.

\section{Some methodological premises and statistical instruments of the diversification versus concentration analysis}


Monopoly and monopsony are the natural limits in any market's analysis and describe together the range or the amplitude of offer and demand in economics. A lot of statistical indicators or coefficients, quantifying the diversification versus concentration (D vs. C) phenomenon can reveal an optimal or inadequate market [12]. The diversification of a distribution of data, such as the data products of a firm or data products of a market reflects both the number of source of data and also the data and the relative amount of each sources, product, firm, market, or otherwise the major structural information.

Thus, D vs. C becomes an association in which diversification is the inverse of concentration:

$$
D=\frac{1}{C}
$$

In the first step, the data distributions or series of data (one-dimensional or multidimensional, hetero- or homo-grade, etc.) transform the formal data series in specific associated or correlated absolute data. The second step means to quantify a wide range of statistical indicators such as specific frequencies $(f$ or $n)$ or weights $(w)$, both measured as relative values, or to cumulate the data series in an ascending manner $\left(f_{i} \uparrow\right.$ or $n_{i} \uparrow$ and $w_{i} \uparrow$ ) or a descending one $\left(f_{i} \downarrow\right.$ or $n_{i} \downarrow$ and $\left.w_{i} \downarrow\right)$. The statistical and probabilistic thinking have generated the notion of quantiles $(C v)$. Common quantiles are significant cutting points able to divide a distribution into continuous intervals with equal probabilities, or the observed data from a sample in the same manner [13]. Different quantiles have special names:

- quartiles (three points cutting the entire population in four groups),

- deciles (10 groups),

- percentiles (100 groups).

Usually, in the quartiles notion are included the median $(\mathrm{Me})$ as a positional value, which divides royally a series of data into two equal structures, the three quartiles $(Q 1, Q 2$, $Q 3)$ describing the same population in four equal structures, the nine deciles $(D 1, \ldots, D 9)$ in ten equal structures and the 99 percentiles $(C 1, \ldots, C 99)$ in one hundred equal structures. If one researcher needs a solution for any type of quantiles $(C v)$ the generalized calculation means to use the following steps:

- Step 1: ordering frequencies $\left(n_{i}\right)$ and their aggregation (accumulation),

- Step 2: identifying the place of the cutting of quantiles, where $s_{i}$ is the rank and $s$ is the quantile's type,

- Step 3: describing the interval in which the quantiles must result from variation intervals,

- Step 4: quantifying the final value $(C v)$ based on a generalized interpolation relation:

$$
C v_{s-i}=X_{C v}+h \frac{\frac{s_{i}}{s}\left(\sum_{i=1}^{m} n_{i}+1\right)-\sum_{i=1}^{C v\left(s_{i-1}\right)} n_{i}}{n_{C v_{s} \frac{i}{s}}},
$$

where $X_{C v}$ is the lower limit, $h$ is the height, $n_{C v}$ is the specific frequency of the same quantilic interval, and $\sum_{i=1}^{C v(s i-1)} n_{i}$ is the cumulative frequency in an ascending manner of all the intervals up to the quantilic interval [14].

D vs. C indicators describe either the diversification process (sometimes meaning uniformity of probability distribution), or only the concentration phenomenon, and allow to identify the structural trends of the statistical population, starting from a certain distribution usually named egalitarian. For a better perception, cumulative frequencies are usually appreciated and built ascending, expressed as percentage, which is graphically represented in the system of rectangular axes. In the general case, the major visible indicator becomes the D vs. C degree. This figure specific to any data distribution, where characteristic $x_{i}$ is a 
positive and cumulative quantity, representing the degree of real distance or real proximity of that distribution comparing to the classic data of the egalitarian distribution [15], represented as probabilities by the Gini-Lorenz concentration curve as red curve in Fig. 1.

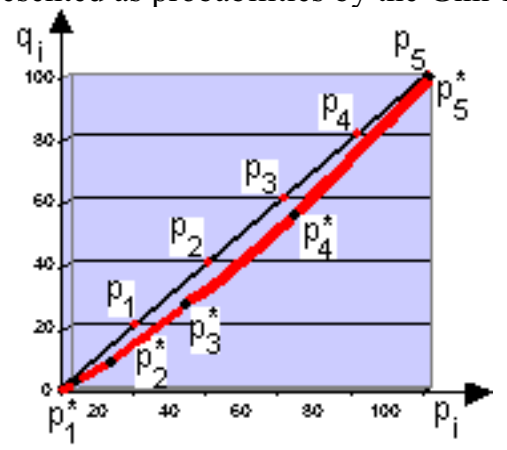

Classical values of probabilities are equal and cumulative ascending:

$$
\begin{aligned}
& \mathrm{p}_{1} \text { or } \mathrm{q}_{1}=20 \% \\
& \mathrm{p}_{2} \text { or } \mathrm{q}_{2}=40 \% \\
& \mathrm{p}_{3} \text { or } \mathrm{q}_{3}=60 \% \\
& \mathrm{p}_{4} \text { or } \mathrm{q}_{4}=80 \% \\
& \mathrm{p}_{5} \text { or } \mathrm{q}_{5}=100 \%
\end{aligned}
$$

probabilities

\section{curve}

Fig. 1. The graphical degree of D vs. C in Gini-Lorenz concentration curve (realized by the authors).

Another classic indicator used to measure the degree of diversification versus concentration process (D vs C) is the coefficient $C_{M l-M e}$ defined by the difference between medial $(M l)$ and median $(M e)$ deviation and expressed by:

$$
C_{M l-M e}=\frac{M l-M e}{\Delta_{x}} \times 100=\frac{M l+M e}{x_{\max }-x_{\min }} \times 100,
$$

where $0 \% \leq C_{M l-M e} \leq 100 \%$.

The more the coefficient described tends to zero, or to the egalitarian distribution, the higher the D vs. C phenomenon becomes null or almost non-existent. The more the same coefficient tends to the maximum value (a value closer to $100 \%$ ) in fact its value translates to a higher concentration and simultaneously the diversification is absent.

Frequency densities are used especially in the case of the series of probabilities resulting from natural groups on unequal intervals, in order to be able to evaluate with their help the real variation of the structures of the entire population or system from one group to another or from one interval to another. Frequency densities are quantified starting from the absolute frequencies and the interval high $\left(f_{i} / h_{i}\right.$ or $\left.n_{i} / h_{i}\right)$ or from the relative frequencies $\left(f_{i}^{*} / h_{i}\right.$ or $\left.n_{i}{ }^{*} / h_{i}\right)$, where $h_{i}$ represents the height of the grouping interval. Frequency densities allow the comparison of empirical or real frequency distributions with the theoretical ones. As the frequency densities decrease towards the ends of the distribution, a relative distributional normality is appreciated, i.e. it is validated that the frequency series benefits from the appearance of a homogenous and even symmetrical distribution.

The measurement of the $\mathrm{D}$ vs $\mathrm{C}$ phenomenon also implies many modern instruments able to identify opposite economic trends for facilitating better decisions and finding optimal solutions [16]. In this paper, we consider modern coefficients and indices instead of classical instruments, all the statistical applied methods of calculus discovered during the last century, not only simpler or more logical, but also including a large number of decimals and precise limits for interpretation of empirical results.

Thus, modern coefficients and indices include:

a) Hirschman-Herfindahl coefficient $\left(C_{H H}\right)$ [17-19] evaluated as the sum of squared structures (specific weights) of the various items (products, companies, geographical areas, etc.) in relation to the total value [20-23]:

$$
C_{H H}=\sum\left(g_{i}\right)^{2},
$$

where $g_{i}=\frac{x_{i}}{\sum x_{i}}$ and with the precise theoretical limits $\frac{1}{n}<g_{i}<1$. 
b) Corrado Gini coefficient $\left(C_{C G}\right)$ quantifying the wealth or the income distribution across statistical population [24], represented graphically through the Gini-Lorenz curve:

$$
C_{C G}=\sqrt{\sum\left(g_{i}\right)^{2}}=\sqrt{C_{H H}},
$$

with a minimal limit $\sqrt{\frac{1}{n}}<C_{C G}<1$, a higher value than 0.3 identifying a major inequality.

c) Gini-Struck coefficient $\left(C_{G S}\right)$ or the normalised form:

$$
C_{G S}=\sqrt{\frac{n \sum\left(g_{i}\right)^{2}-1}{n-1}} ; C_{G S} \in\{0,1\} \text {. }
$$

Data and metadata, together with statistical experience of the authors are the essential elements of the applied D vs. C analysis phenomenon in this paper, able to generate matrices, $R$-squared and finally to offer some major forecasting models of the market diversification process in the housing construction market in Siberia.

\section{Data and Baseline Empirical Findings}

Our sample is panel dataset that consists of measured diversification and concentration indexes for 10 Siberian regions over the observation period 2000-2020 for 6 indicators of regional socio-economic growth: regional population $\left(x_{1}\right)$, total income of households $\left(x_{2}\right)$, housing construction $\left(x_{3}\right)$, urban and rural housing stock (denote, respectively, $x_{4}$ and $x_{5}$ ), and investments which made in the form of capital assets $\left(x_{6}\right)$. The empirical analysis is based on macro-region of Siberian Federal District level data obtained from the enterprise survey by the Federal State Statistics Service of the Russian Federation. Tables 1 and 2 report the dataset of diversification for all 6 explanatory variables measured both indexes in $\mathrm{HH}$ and GS, respectively.

Table 1. Calculation of coefficient $\mathrm{HH}$ on all valid variables of the sample*.

\begin{tabular}{|c|c|c|c|c|c|c|}
\hline Year & $\boldsymbol{x}_{\mathbf{1}}$ & $\boldsymbol{x}_{\mathbf{2}}$ & $\boldsymbol{x}_{\mathbf{3}}$ & $\boldsymbol{x}_{\mathbf{4}}$ & $\boldsymbol{x}_{\mathbf{5}}$ & $\boldsymbol{x}_{\mathbf{6}}$ \\
\hline 2000 & 0.1363 & 0.1552 & 0.1399 & 0.1478 & 0.1493 & 0.1724 \\
\hline 2001 & 0.1362 & 0.1563 & 0.1454 & 0.1477 & 0.1495 & 0.1641 \\
\hline 2002 & 0.1362 & 0.1470 & 0.1408 & 0.1476 & 0.1496 & 0.1498 \\
\hline 2003 & 0.1361 & 0.1444 & 0.1463 & 0.1473 & 0.1500 & 0.1450 \\
\hline 2004 & 0.1360 & 0.1430 & 0.1462 & 0.1466 & 0.1484 & 0.1580 \\
\hline 2005 & 0.1359 & 0.1443 & 0.1478 & 0.1460 & 0.1475 & 0.1639 \\
\hline 2006 & 0.1358 & 0.1411 & 0.1534 & 0.1458 & 0.1479 & 0.1482 \\
\hline 2007 & 0.1356 & 0.1418 & 0.1489 & 0.1458 & 0.1477 & 0.1457 \\
\hline 2008 & 0.1355 & 0.1391 & 0.1459 & 0.1455 & 0.1477 & 0.1545 \\
\hline 2009 & 0.1354 & 0.1414 & 0.1442 & 0.1452 & 0.1472 & 0.1798 \\
\hline 2010 & 0.1353 & 0.1401 & 0.1479 & 0.1464 & 0.1440 & 0.1698 \\
\hline 2011 & 0.1352 & 0.1393 & 0.1478 & 0.1460 & 0.1440 & 0.1628 \\
\hline 2012 & 0.1352 & 0.1387 & 0.1478 & 0.1461 & 0.1462 & 0.1686 \\
\hline 2013 & 0.1351 & 0.1392 & 0.1468 & 0.1467 & 0.1430 & 0.1646 \\
\hline 2014 & 0.1350 & 0.1385 & 0.1581 & 0.1455 & 0.1451 & 0.1591 \\
\hline 2015 & 0.1350 & 0.1364 & 0.1615 & 0.1461 & 0.1453 & 0.1755 \\
\hline 2016 & 0.1350 & 0.1363 & 0.1597 & 0.1458 & 0.1441 & 0.1838 \\
\hline 2017 & 0.1349 & 0.1354 & 0.1511 & 0.1460 & 0.1407 & 0.1779 \\
\hline 2018 & 0.1349 & 0.1380 & 0.1552 & 0.1453 & 0.1415 & 0.1686 \\
\hline 2019 & 0.1348 & 0.1374 & 0.1581 & 0.1446 & 0.1398 & 0.1610 \\
\hline 2020 & 0.1347 & 0.1374 & 0.1589 & 0.1440 & 0.1390 & 0.1597 \\
\hline
\end{tabular}

Note: * Authors' calculation is based on HH values. 
We use the following regression equations to estimate the impact of diversification and concentration processes on (i) housing construction productivity, (ii) diversification and concentration processes within housing local market, (iii) regional GDP growth and (iv) regional GDP growth by housing construction sector:

$$
y=\alpha+\beta \times D v s . C+\gamma^{\prime} \mathbf{X}+\varepsilon
$$

where Dvs.C is an indicator variable that assumed to quantify the dependence degree of concentration on the degree of diversification in regional product and resource local markets; $\mathbf{X}$ is the vector of control variables; and $\varepsilon$ is the error term.

Table 2. Calculation of coefficient GS on all valid variables of the sample*.

\begin{tabular}{|c|c|c|c|c|c|c|}
\hline Year & $\boldsymbol{x}_{\mathbf{1}}$ & $\boldsymbol{x}_{\mathbf{2}}$ & $\boldsymbol{x}_{\mathbf{3}}$ & $\boldsymbol{x}_{\mathbf{4}}$ & $\boldsymbol{x}_{\mathbf{5}}$ & $\boldsymbol{x}_{\mathbf{6}}$ \\
\hline 2000 & 0.2008 & 0.2227 & 0.2106 & 0.2304 & 0.2340 & 0.2836 \\
\hline 2001 & 0.2007 & 0.2255 & 0.2247 & 0.2303 & 0.2346 & 0.2670 \\
\hline 2002 & 0.2005 & 0.2286 & 0.2130 & 0.2299 & 0.2349 & 0.2352 \\
\hline 2003 & 0.2002 & 0.2222 & 0.2267 & 0.2292 & 0.2357 & 0.2237 \\
\hline 2004 & 0.2000 & 0.2187 & 0.2264 & 0.2275 & 0.2318 & 0.2540 \\
\hline 2005 & 0.1997 & 0.2219 & 0.2305 & 0.2261 & 0.2297 & 0.2664 \\
\hline 2006 & 0.1994 & 0.2137 & 0.2436 & 0.2257 & 0.2307 & 0.2313 \\
\hline 2007 & 0.1990 & 0.2156 & 0.2331 & 0.2256 & 0.2301 & 0.2253 \\
\hline 2008 & 0.1987 & 0.2085 & 0.2258 & 0.2248 & 0.2302 & 0.2461 \\
\hline 2009 & 0.1984 & 0.2145 & 0.2215 & 0.2241 & 0.2289 & 0.2978 \\
\hline 2010 & 0.1980 & 0.2112 & 0.2308 & 0.2270 & 0.2211 & 0.2786 \\
\hline 2011 & 0.1978 & 0.2089 & 0.2305 & 0.2261 & 0.2211 & 0.2641 \\
\hline 2012 & 0.1977 & 0.2073 & 0.2304 & 0.2264 & 0.2265 & 0.2760 \\
\hline 2013 & 0.1975 & 0.2088 & 0.2280 & 0.2279 & 0.2186 & 0.2679 \\
\hline 2014 & 0.1973 & 0.2068 & 0.2541 & 0.2250 & 0.2239 & 0.2562 \\
\hline 2015 & 0.1972 & 0.2012 & 0.2614 & 0.2262 & 0.2242 & 0.2896 \\
\hline 2016 & 0.1971 & 0.2009 & 0.2576 & 0.2256 & 0.2214 & 0.3051 \\
\hline 2017 & 0.1970 & 0.1983 & 0.2383 & 0.2261 & 0.2127 & 0.2942 \\
\hline 2018 & 0.1969 & 0.2054 & 0.2477 & 0.2243 & 0.2147 & 0.2760 \\
\hline 2019 & 0.1968 & 0.2040 & 0.2541 & 0.2227 & 0.2104 & 0.2603 \\
\hline 2020 & 0.1966 & 0.2038 & 0.2570 & 0.2250 & 0.2100 & 0.2584 \\
\hline
\end{tabular}

Note: * Source: Authors' calculation is based on GS values.

Annual dynamics of calculated indexes illustrate multidirectional trends in the development of local markets of goods and resources of the vast macro-region of the Siberian Federal District without taking into account their influence on each other as a result of conjugate interaction. This will be done by us as the next step of the study. Summary statistics in Table 3 show non-substantial variations in calculated and selected dataset. In particular, the standard deviations are generally much smaller than the corresponding means, which is characteristic of the macro-region, whose development indicators, due to their intrinsic spatial properties, have a certain degree of inertia.

Table 3. Descriptive statistics of HH and GS values for all the series of valid variables *.

\begin{tabular}{|l|c|c|c|c|c|c|}
\hline \multicolumn{1}{|c|}{ Descr. Stat. } & $\boldsymbol{x}_{\mathbf{1}}$ & $\boldsymbol{x}_{\mathbf{2}}$ & $\boldsymbol{x}_{\mathbf{3}}$ & $\boldsymbol{x}_{\mathbf{4}}$ & $\boldsymbol{x}_{\mathbf{5}}$ & $\boldsymbol{x}_{\mathbf{6}}$ \\
\hline Mean $H H$ & 0.13544 & 0.14146 & 0.15008 & 0.14609 & 0.14560 & 0.16347 \\
\hline Std. Dev. $H H$ & 0.00051 & 0.00560 & 0.00630 & 0.00097 & 0.00335 & 0.01103 \\
\hline Min $H H$ & 0.13470 & 0.13540 & 0.13993 & 0.14400 & 0.13900 & 0.14502 \\
\hline Max $H H$ & 0.13627 & 0.15633 & 0.16149 & 0.14776 & 0.15001 & 0.18379 \\
\hline Mean $G S$ & 0.19844 & 0.21183 & 0.23552 & 0.22647 & 0.22502 & 0.26461 \\
\hline Std. Dev. $G S$ & 0.00141 & 0.00873 & 0.01480 & 0.00208 & 0.00819 & 0.02330 \\
\hline Min $G S$ & 0.19660 & 0.19833 & 0.21063 & 0.22268 & 0.21000 & 0.22366 \\
\hline Max $G S$ & 0.20076 & 0.22862 & 0.26138 & 0.23037 & 0.23572 & 0.30513 \\
\hline
\end{tabular}

Note: * Authors' calculation is based on HH and GS values. 
Table 4 presents the results for basic specification, testing effects during selected period.

Table 4. OLS regression estimation for the selected model for the share of regional GDP generations from construction measured in $\mathrm{HH}$ and GS as the dependent variable.

\begin{tabular}{|l|c|c|c|c|}
\hline \multicolumn{1}{|c|}{ Variable } & Coeff. & $\boldsymbol{t}$-Stat. & Std. err. & $\boldsymbol{p}$-Value \\
\hline$x_{1} *$ & -9.382343 & 1.837759 & -5.105317 & 0.0001 \\
\hline$x_{1} * *$ & -8.011979 & 1.554822 & -5.152989 & 0.0001 \\
\hline$x_{2} *$ & -0.760607 & 0.190068 & -4.001760 & 0.0008 \\
\hline$x_{2}{ }^{* *}$ & -1.296768 & 0.250226 & -5.182387 & 0.0001 \\
\hline$x_{6} *$ & 0.120143 & 0.127951 & 0.938973 & 0.3595 \\
\hline$x_{6} * *$ & 0.128840 & 0.142675 & 0.903035 & 0.3778 \\
\hline$x_{4} *$ & -4.382367 & 1.108269 & -3.954245 & 0.0009 \\
\hline$x_{4} * *$ & -4.572702 & 1.251416 & -3.654022 & 0.0017 \\
\hline$x_{5} *$ & -1.228592 & 0.325650 & -3.772735 & 0.0013 \\
\hline$x_{5} * *$ & -1.190579 & 0.311996 & -3.816011 & 0.0012 \\
\hline
\end{tabular}

Note: *Refers to variables interpreted as HH. ** Refers to variables interpreted as GS.

On the one hand, coefficients measuring the effect diversification within dataset are negative and highly statistically significant. In particular, they indicate that concentration of economic activity and increasing interactions within local markets provided urbanization. On the other hand, variables such as investment diversification measured both indexes in $\mathrm{HH}$ and GS, present a $p$-Value higher than 0.05 and thus are explicitly linked with not construction diversification also measured both indexes in $\mathrm{HH}$ and GS, respectively, suggesting this doesn't happen at the expense of investment.

Table 5. Econometric models of HH and GS values based on multivariate OLS regression.

\begin{tabular}{|c|c|c|c|c|c|}
\hline Regressors & (2) & (3) & (4) & (5) & (6) \\
\hline$x_{1} H H$ & $\begin{array}{c}-12.992 * * * \\
{[0.789]}\end{array}$ & $\begin{array}{c}-120.348^{* * *} \\
{[13.165]}\end{array}$ & & & \\
\hline$x_{1} G S$ & & & $\begin{array}{c}-4.789 * * * \\
{[0.433]}\end{array}$ & $\begin{array}{c}-36.669 * * * \\
{[4.889]}\end{array}$ & \\
\hline$x_{2} H H$ & $\begin{array}{c}-0.319 * * * \\
{[0.072]}\end{array}$ & & $\begin{array}{c}-0.109 \\
{[0.067]}\end{array}$ & & \\
\hline$x_{2} G S$ & & & & & $\begin{array}{l}21.731 * * \\
{[10.348]}\end{array}$ \\
\hline$x_{6} G S$ & & & $\begin{array}{l}-0.019 * \\
{[0.009]}\end{array}$ & & \\
\hline$x_{3} H H$ & & & & & $\begin{array}{l}24.237^{*} \\
{[9.209]}\end{array}$ \\
\hline$x_{4} G S$ & & & $\begin{array}{c}-0.472 * * * \\
{[0.142]}\end{array}$ & $\begin{array}{l}-4.156^{* *} \\
{[1.8869]}\end{array}$ & \\
\hline$x_{5} H H$ & & $\begin{array}{c}7.313 * * * \\
{[2.003]}\end{array}$ & & & \\
\hline$x_{5} G S$ & & & & $\begin{array}{c}2.553 * * * \\
{[0.719]}\end{array}$ & \\
\hline Adj. R-squared & 0.988 & 0.908 & 0.989 & 0.926 & 0.602 \\
\hline Log likelihood & 119.01 & 63.32 & 121.62 & 66.28 & -12.01 \\
\hline$F$-statistic & $828.6759 * * *$ & $100.4047 * * *$ & $473.5769 * * *$ & $85.6167 * * *$ & $10.5749 * * *$ \\
\hline$D W$ stat & 1.479 & 1.165 & 1.656 & 1.853 & 1.003 \\
\hline Observation & 210 & 210 & 210 & 210 & 210 \\
\hline
\end{tabular}

Note: The dependent variable in all columns is regional GDP in natural log, in columns 5 and 6 is regional GDP growth by housing construction sector. Also, $\mathrm{HH}$ means variable interpreted as $\mathrm{HH}$ measure and GS means variable interpreted as GS measure, referring to definitions in (4) and (6). Robust standard errors are in parentheses. Significant: ${ }^{*} p<0.1 * * p<0.05 * * * p<0.01$ 
We estimate model (7) again, replacing the measures of diversification employed so far with regional GDP growth and regional GDP growth by housing construction sector. Based on the estimates in Table 5, we draw the main conclusion that in the Siberian Federal District macroregion, the diversification of housing stock in rural areas contributes to the growth of the region's GDP and the growth of the sector's GDP. The expected positive and statistically significant influence is also exerted by such variables as diversification of housing construction and growth of household incomes, which is associated with an increase in business activity of local markets for goods and resources.

\section{Conclusions}

We estimate the effect regional economic diversification has on the resiliency of the Siberian housing construction market, treating the sectoral and spatial variation within local emerging markets. Our study demonstrates that diversity dampens both the magnitude and the dispersion of the effects of a concentration on local labor and housing markets.

The study of the Siberian macroregion is important for the development of the spatial economy and understanding which processes lead to economic growth in these vast territories. Using the proposed techniques of analysis of concentration and diversification in the local housing market, we found the relationship between the factors of local markets and explained that further increasing urbanization leads not only to a high level of concentration of economic activity. Local markets for goods and resources do not have the opportunity to expand by increasing the density of local labor markets. As a result, the efficiency of regional production declines as transportation costs and the costs of interaction among economic agents rise. Increasing concentration at the expense of diversification leads to a shortage of land and an already tangible shortage of urban development. Many peripheral, non-urbanized territories are gradually becoming a permanent part of urban agglomerations at the expense of rural areas. The depressed local housing market has a negative impact on adjacent local markets, leading to general structural depression and spillover large increase in construction prices, and as a consequence, a deterioration of the demographic situation due to increasing of labor outflows, a decrease in the birth rate and an increase in the share of the disabled population.

As a result of the discovery of causal relationships between different levels of influence of local market factors on the level of diversification, we have found an explanation of the nature of the ongoing trends, which can also be applied to territories with similar naturalgeographical and socioeconomic conditions to improve policies to expand the spatial distribution of economic activity.

The increase in regional productivity, the main factor of which is industrial concentration, is due to active urbanization, which attracts flows of goods and resources, and increases the density of solvent demand per square of space. To further avoid a jump in construction prices, inflationary processes and spatial divergence, should be leveled by stimulating the diversification of local emerging markets, for example, through infrastructure development, which we will study in our future work.

\section{References}

1. D. Kahneman, Thinking, Fast and Slow (London: Penguin Books, 2011)

2. S. K. Mishra, B. Kumar, Disparities in Globalization of the World Economies, MPRA Paper 42127 (2012) available online at: https://mpra.ub.uni-muenchen.de/42127/ Accessed on the 2nd of April 2021. 
3. R. Gupta, X. Sun, Empirical Economics 58(5) 2309-2332 (2020)

4. J. M. Gaspar, New Economic Geography: Economic Integration and Spatial Imbalances, in Colombo S. (eds) Spatial Economics Volume I. Palgrave Macmillan, Cham (2020) https://doi.org/10.1007/978-3-030-40098-9_4

5. J. Bonet, A. M. Roca, Journal of Regional Research 14 61-80 (2009)

6. C. Li, K. Wu, X. Gao, Environ Dev Sustain 22 2941-2965 (2020)

7. M. Badia-Miró, Spatial Inequality in Chile in the Long Run: A Paradox of Extreme Concentration in the Absence of Agglomeration Forces (1890-2017), in TiradoFabregat D.A., Badia-Miró M., Willebald H. (eds) Time and Space. Palgrave Studies in Economic History. Palgrave Macmillan, Cham (2020)

8. X. Zhang, J. Yao, K. Sila-Nowicka et al., Ann Reg Sci 66 439-461 (2021)

9. E. Freitakas, The impact's of loan's portfolio concentration and diversification to the banking sector. Seven years of Bulgaria's membership in the European Union (2013)

10. V. Di Giacinto, G. Micucci, A. Tosoni, The Annals of Regional Science 65 (2020)

11. R. Capello, S. Cerisola, Growth and Change 51(4) 1440-1453 (2020)

12. M. Hall, N. Tideman, Journal of the American statistical association 62162 (1967)

13. R. J. Serfling, Approximation theorems of mathematical statistics, 162 (John Wiley \& Sons, 2009)

14. G. Săvoiu. Statistica generală cu aplicaţii în contabilitate. Editura Universitară (2012)

15. C. Gini, The economic journal 31(121): 124-126 (1921)

16. P. Bharati, U. K. De, M. Pal, A modified diversity index and its application to crop diversity in Assam, India, in AIP Conference Proceedings 1643(1), 19-29 (2015) Available online at: http://dx.doi.org/10.1063/1.4907421, Accessed on the 5th of April 2021.

17. O. C. Herfindahl, Concentration in the US steel industry (Unpublished doctoral dissertation, Columbia University, 1950)

18. A. O. Hirschman, American Economic Review 54 761-62 (1964)

19. S. Calkins, Calif. L. Rev. 71402 (1983)

20. A. O. Hirschman, National power and the structure of foreign trade (Vol. 105). Univ of California Press. (1980)

21. G. Săvoiu, M. Siminică, Amfiteatru Economic 18(43) 503-520 (2016)

22. R. S. Nirpal, R. R. Suryawanshi, R. A. Shelke, S. M. Londe, Journal of Pharmacognosy and Phytochemistry 8(5) 191-195 (2019)

23. J. Beutel, Economic Diversification and Sustainable Development of GCC Countries, in G. Luciani and T. Moerenhout, 2021. When Can Oil Economies Be Deemed Sustainable? Palgrave Macmillan, Singapore: Springer Nature Singapore Pte Ltd (2021)

24. C. Gini, Variabilità e mutabilità (Variability and Mutability) Cuppini, Bologna, 156 (1912) 